\title{
Equilibrium and rate of iron(III) extraction from chloride solutions by individual hydrophobic extractants and their mixtures
}

\author{
Katarzyna Staszak ${ }^{1}$, Ryszard Cierpiszewski², Krystyna Prochaska ${ }^{*}$ \\ ${ }^{1}$ Poznan University of Technology, Institute of Chemical Technology and Engineering, pl. M. Skłodowskiej-Curie 2, \\ 60-965 Poznań, Poland, e-mail: Krystyna.Prochaska@put.poznan.pl, \\ ${ }^{2}$ Poznan University of Economics, Faculty of Commodity Science, al. Niepodleglości 10, 61-875 Poznań, Poland,
}

\begin{abstract}
The main goal of this work was to study and compare the rate of iron(III) extraction from chloride solutions by commercial extractants: Alamine 336, TOPO and LIX 54 and their mixtures. Using the interfacial tension data, obtained for mixed systems, the values of surface mole fraction and molecular interaction parameter of extractants were estimated. Determination of the extraction rates was performed by using the Lewis-type stirred transfer cell. It was found that the extraction efficiency of extractants are changed in the following order: Alamine 336>TOPO $>\beta$-diketone. The addition of a chelating extractant to the system decreases the extraction efficiency, for example the addition of $\beta$-diketone to TOPO decreases the extraction efficiency by about $50 \%$.
\end{abstract}

Keywords: extraction, iron(III), Alamine 336, TOPO, $\beta$-diketone.

\section{INTRODUCTION}

Iron is a naturally occurring element that also enters the environment from industrial sources. The EC Drinking Water Directive (98/83/EEC) lists iron as the indicator parameter in Part $\mathrm{C}$ at the maximum permissible value of $0.2 \mathrm{mg} / \mathrm{L}$. In the former Directive (80/778/EEC) a guide value, the level considered to be ideal, had been set at 0.05 $\mathrm{mg} / \mathrm{L}$. In Poland after acceding to European Union the maximum permissible value of iron in the water has been changed from 0.5 to $0.2 \mathrm{mg} / \mathrm{L}$.

Solvent extraction is usually applied the separation and/ or concentration of valuable metals. Iron is commonly found in the aqueous solutions in the case of the recovery of non-ferrous metals by hydrometallurgical processes, accompanying all these metals. In the world's hydrometallurgical process nearly 18 million ton/year of iron are produced. Moreover, removal of iron from aqueous wastes is also very important from the ecological point of view, especially after mentioning the above change of the standard for iron in the water in Poland. Commercially available organophosphorous extractants can be employed to remove iron in some hydrometallurgical processes. Among neutral extractants, tributylphosphate (TBP) ${ }^{1}$ and methyl iso-butyl ketone (MIBK) ${ }^{2}$ have been used extensively for the extraction of iron(III) from hydrochloric acid solutions. Organophosphorus acid derivatives such as di-2-ethylhexylphosphoric acid (DEHPA) ${ }^{3-5}$ or amines ${ }^{6,7}$ have also been used. All these extractants have their own drawbacks: MIBK has a low flash point and high solubility in the aqueous phase; the use of TBP usually leads to the third phase formation; a high acid concentration is required to strip iron(III) from the acidic extractants such as DEHPA ${ }^{3}$. Thus, the development of new extraction systems for the extraction of iron(III) seems to be very important.

The aim of this work was to investigate the rate of iron(III) extraction from chloride solutions by three commercial extractants: trioctylphosphine oxide (TOPO), Alamine 336 with trialkylamine $\left(\mathrm{C}_{8}: \mathrm{C}_{10}=2: 1\right)$ as an active substance and LIX 54 with 1-phenyldecane-1,3-dione as active substance and their mixtures. Assuming that the complexation of iron(III) in the considered systems probably occur at the interface, the adsorption properties of the extractants at the hydrocarbon/water interface were also studied.

\section{EXPERIMENTAL}

TOPO, LIX 54 and Alamine 336 were used as extractants. Only TOPO was a pure compound. The others were commercial reagents and used as delivered. Toluene and low aromatic kerosene Exxsol D220/230 (Deutsche Exxon Chemical, ESSO A.G.) were used as organic diluents. The concentration of the extractants was changed from $30 \%$ to $100 \% \mathrm{v} / \mathrm{v}$.

The extraction was carried out in separatory funnels using the same volumes $\left(10 \mathrm{~cm}^{3}\right)$ of both phases. The phases were mechanically shaken for 1 hour and then allowed to phase separate (usually more than 1 hour). Demineralized water $\left(10 \mathrm{~cm}^{3}\right)$ was used for stripping.

The kinetics of iron extraction was investigated using a constant interfacial area Lewis-type cell $\left(21^{\circ} \mathrm{C}\right)$. The handmade apparatus provided a constant interfacial area of $16.6 \mathrm{~cm}^{2}$, volume of aqueous or organic phase was equal to $95 \mathrm{~cm}^{3}$. Samples of organic phases $\left(1 \mathrm{~cm}^{3}\right)$ were withdrawn after appropriate periods of time. The sample of the organic phase was stirred with $10 \mathrm{~cm}^{3}$ of water and the iron concentration in the aqueous phase was determined. Fresh organic solution $\left(1 \mathrm{~cm}^{3}\right)$ was added to the stirred cell to maintain a constant volume ratio. The stirrer speeds in the organic and aqueous solutions were kept in the range of $30-150 \mathrm{rpm}$ to maintain a flat and stable interface.

The concentration of iron was determined in the aqueous phase before and after extraction and after stripping for equilibrium experiments. For kinetics experiments iron concentration was measured only after stripping, as was mentioned above. The concentration of iron was determined by atomic absorption spectroscopy using a Varian SPECTR AA800. The measurements were carried out at $248.3 \mathrm{~nm}$, with a relative error of analysis less than $3 \%$.

The FTIR spectra were recorded at $2 \mathrm{~cm}^{-1}$ resolution using a Bruker IFS 113v spectrometer (range of $4000-$ 
$500 \mathrm{~cm}^{-1}$ ). Spectra for the individual species were run in the liquid film or in the $\mathrm{KBr}$ disk, for the mixed systems in chloroform solution with the total concentration $10^{-1} \mathrm{~mol} / \mathrm{L}$.

The interfacial tension was measured by the drop volume method with a Lauda TVT1 tensiometer with an experimental error of $0.1 \mathrm{mN} / \mathrm{m}$. The measurements were carried out at $21 \pm 0.1^{\circ} \mathrm{C}$ with pre-saturated phases (by automatically shaking for $5 \mathrm{hrs}$ ). Freshly distilled toluene (POCh S.A.) and re-distilled water were used in preparation the solutions.

\section{RESULTS AND DISCUSSION}

The iron(III) extraction from chloride acidic solutions with different concentrations of $\mathrm{HCl}$ in five systems were investigated. Three systems with individual extractant (Alamine 336, TOPO, LIX 54) as well as two systems with equimolar mixture of TOPO with Alamine 336 or LIX 54 were considered. The obtained results are presented in Figure 1. The high efficiency for iron(III) extraction of considered reagents was demonstrated by the extraction isotherms presented for $0.1 \mathrm{M}$ solutions of TOPO and Alamine 336 in toluene. Solutions of TOPO and Alamine 336 were loaded up to 2.67 and $2.51 \mathrm{~g} / \mathrm{L}$ $\mathrm{Fe}(\mathrm{III})$, respectively. However the mixture of these compounds or TOPO/LIX 54 extracted less iron(III) than the individual reagents. The chelating extractant did not extract iron(III) from hydrochloric acid solutions. Only a small amount of iron(III) was extracted in this case.

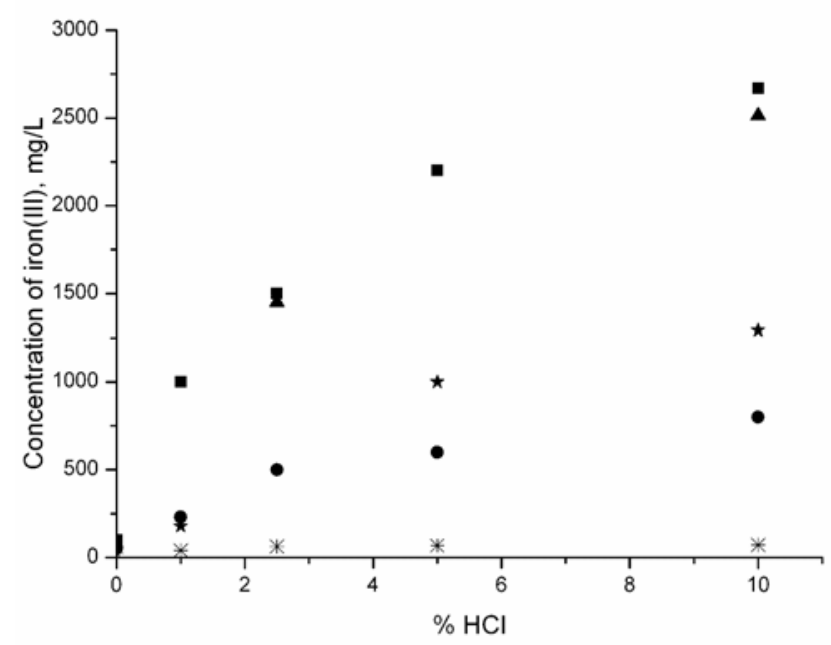

Figure 1. Extraction of iron(III) from hydrochloric acid solution (initial concentration of $\mathrm{Fe}(\mathrm{III}) 5 \mathrm{~g} / \mathrm{L}$, concentration of extractants $-0.1 \mathrm{M}$ in toluene, $\operatorname{ALAMINE}^{\circledR} 336(\mathbf{\square}), \operatorname{TOPO}(\boldsymbol{\Delta})$, ALAMINE $^{\circledR} 336$ + TOPO (•), TOPO+ LIX $54(\star)$, ALAMINE $^{\circledR} 336$ in Exxsol D220/230 (*)

Extraction of $\mathrm{Fe}(\mathrm{III})$ by TOPO and Alamine 336 increased significantly as the concentration of neutral iron(III) chloride and $\mathrm{HCl}$ increased. For instance, in the $10 \% \mathrm{HCl}$, the mole fractions of $\mathrm{Fe}(\mathrm{III})$ chlorocomplexes were estimated approximately to be $0.18,0.49,0.26$ and 0.08 for $\mathrm{FeCl}_{3}, \mathrm{FeCl}^{2+}, \mathrm{FeCl}^{2+}$ and $\mathrm{Fe}^{3+}$, respectively ${ }^{8}$. These cationic species would not be extracted with either the solvating or basic reagents. It can be assumed that in the case of $\mathrm{Fe}$ (III) extraction from acid chloride solutions the molecules of extractants can react only with the chlorocomplex $\mathrm{FeCl}_{3}$. The molar fraction of $\mathrm{FeCl}_{3}$ in the aqueous phase depends on the chloride concentration and on the ionic strength (Figure 2) and as shown the molar fraction of this complex increases when the chloride concentration rises. The estimated values of molar fractions are in good agreement with the results presented by Biswas and Begun'. The solvating (S) and basic (B) reagents could extract the neutral iron(III) chlorocomplex according to the reactions: $\mathrm{FeCl}_{3 \mathrm{w}}+2 \mathrm{~S}_{\mathrm{o}}=\mathrm{FeCl}_{3} \cdot 2 \mathrm{~S}_{\mathrm{o}}$ and $\mathrm{FeCl}_{3 \mathrm{w}}+\mathrm{B} \cdot \mathrm{HCl}_{\mathrm{o}}=(\mathrm{BH}) \mathrm{FeCl}_{4 \mathrm{o}}$.

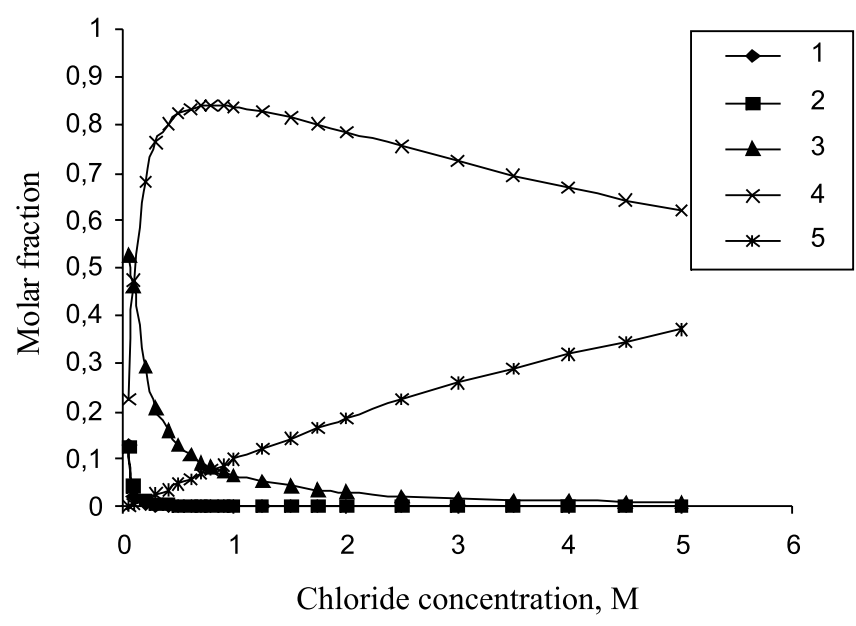

Figure 2. Influence of chloride concentration on molar fractions of $\mathrm{FeCl}_{\mathrm{i}}^{3-\mathrm{i}}$ in the aqueous phase ([Fe(III) $-0,01 \mathrm{M}, 1 / \mathrm{Fe}^{3+}, 2-\mathrm{FeCl}^{2+}, 3-\mathrm{FeCl}_{2}^{2+}, 4-\mathrm{FeCl}_{3}$, $\left.5-\mathrm{FeCl}_{4}^{-}\right)$

In Figure 3 the results of kinetics of iron extraction procedure are shown for system containing a mixture of LIX 54 and TOPO. The concentration of Fe(III) in the organic phase increases almost linearly with time from zero up to about 40 minutes. The slopes of linear relations were used to determine the fluxes of iron transfer from the aqueous to the organic phase. The initial extraction rates estimated for the considered systems are shown in Table 1 (the initial concentration $5 \mathrm{~g} / \mathrm{L}$ of iron). These results indicated that the initial extraction rate is approximately proportional to the speed in the range from 30 to $120 \mathrm{rpm}$. Under $150 \mathrm{rpm}$ the interface becomes unstable and the extraction increases very fast. On this basis, 90

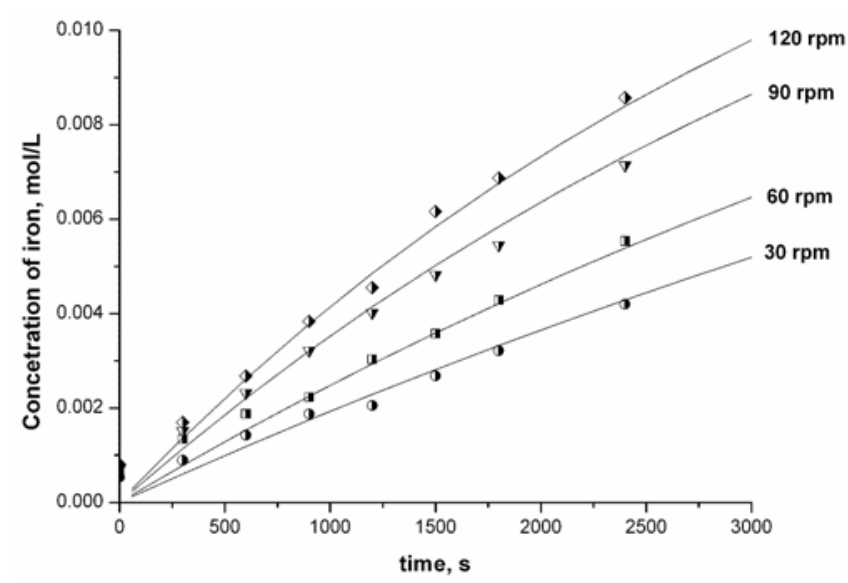

Figure 3. Effect of the stirring speed on the initial rate of the extraction of iron(III) by $0.05 \mathrm{M}$ TOPO and $0.05 \mathrm{M}$ LIX54 in toluene; aqueous phase: $5 \mathrm{~g} / \mathrm{L}$ $\mathrm{Fe}(\mathrm{III}), \mathrm{HCl}$ : stirring speed: $(\bullet) 180 \mathrm{rpm},(\boldsymbol{\nabla}) 140$ rpm, (অ) $90 \mathrm{rpm},(\bullet) 60 \mathrm{rpm}$ 
Table 1. Initial rate of iron extraction

\begin{tabular}{|c|c|c|c|c|}
\hline \multirow{2}{*}{$\begin{array}{ll} & \text { Extractant } \\
\mathrm{rpm} & \\
\end{array}$} & \multicolumn{4}{|c|}{$\begin{array}{c}\text { Initial rate of extraction } \\
r \times 10^{6}\left[\mathrm{~mol} / \mathrm{dm}^{2} \mathrm{~s}\right]\end{array}$} \\
\hline & 30 & 60 & 90 & 120 \\
\hline ALAMINE 336 in toluene & 198 & 730 & 1580 & 2180 \\
\hline $\begin{array}{l}\text { ALAMINE } 336 \text { and TOPO }(1: 1 \\
\mathrm{mol} / \mathrm{mol}) \text { in toluene }\end{array}$ & 32.9 & 80 & 91.3 & 210 \\
\hline TOPO toluene & 140 & 871 & 1290 & 1500 \\
\hline $\begin{array}{l}\text { TOPO + LIX } 54(1: 1 \mathrm{~mol} / \mathrm{mol}) \\
\text { toluene }\end{array}$ & 130 & 907 & 1230 & 1430 \\
\hline LIX54 toluene & & 52 & 59 & 65 \\
\hline $\begin{array}{l}\text { ALAMINE } 336 \text { in Exxsol } \\
\text { D220/230 }\end{array}$ & 0 & 4.6 & 5.5 & 6.8 \\
\hline
\end{tabular}

rpm was selected for the study of the interfacial phenomena due to the very good stability of the interfacial surface and high extraction rate. The best results were obtained for the system containing Alamine 336 in toluene, where the rate of extraction is almost $20 \%$ higher in comparison to the results with TOPO (the initial rate at $60 \mathrm{rpm}$ was lower than expected but additional experiments were not done). The addition of a second extractant led to a significant decrease in the initial rate of extraction. Moreover, it was found that the rate of $\mathrm{Fe}$ (III) transport from acidic water solution to the organic phase by using LIX 54 is very slow in comparison to the system with TOPO or Alamine 336. The results obtained in the systems with toluene are much higher in comparison to the systems where Exxsol D220/230 was used as a diluent. Good agreement between the rate of extraction and equilibrium of extraction was observed.

Effect of iron(III) concentration on the initial extraction rate was also studied in our previous paper ${ }^{\mathbf{1 0}}$. The obtained results show that the rate of extraction is affected by the concentration of iron(III) and as was stated the rate of extraction increases with the increase of the concentration of metal ions in the system.

Mass transfer of Fe(III) between an aqueous and an organic phase $\left(k_{1}\right)$ was also studied, too. The experimental mass transfer coefficients can be expressed by the equation:

$k_{1}=\frac{V_{1}}{A t} \ln \frac{C_{1}^{0}}{C_{1}}$

where: $A$ - area of interface, $V$ volume of phase, $C$ - concentration. The obtained results are shown in Table 2.

According to Bandyopadhyay et. al.1 ${ }^{11}$ the best model of calculation of mass transfer coefficients for extraction can be obtained by using the following correlation:

$\frac{k_{1} L}{D}=0.187 S c_{1}^{0.33} \operatorname{Re}^{0,97}\left(\frac{\mu_{2}}{\mu_{1}}\right)^{1,6}\left(1+\frac{\operatorname{Re}_{2} \mu_{2}}{\operatorname{Re}_{1} \mu_{1}}\right)$

A comparison between the experimental mass transfer coefficients and the values of $k_{1}$ calculated from the above correlation are in good agreement, especially in the region of high speed of the stirrer rotation (Table 2).

Table 2. Experimental and predicted mass transfer coefficients, $\mathrm{m} / \mathrm{s} \cdot 10^{6}$

\begin{tabular}{|l|c|c|}
\hline & $60 \mathrm{rpm}$ & $90 \mathrm{rpm}$ \\
\hline ALAMINE 336 & 0.487 & 2.17 \\
\hline ALAMINE 336 + TOPO & 0.243 & 0.444 \\
\hline Bandyopadhyay's equation & 0.691 & 2.01 \\
\hline
\end{tabular}

\section{Modeling of the mass transfer in a Lewis cell}

The concentration of metal ions in the aqueous and organic phase can be evaluated by the following equations $^{12}$ :

a) $V_{w} \frac{d C_{w}(t)}{d t}=k \cdot S\left(C_{w}(t)-\frac{C_{0}(t)}{D}\right)$ in the aqueous phase:

b) $V_{o} \frac{d C_{o}(t)}{d t}=k \cdot S\left(C_{w}(t)-\frac{C_{0}(t)}{D}\right)$ in the organic phase:

where: $C$ - concentration of metal, $D$ - distribution coefficient, $A$ - interfacial surface, $V$ - phase volume, $t$ - time, " 0 " - initial value. Rearranging both equation gives the time dependent for metal ions concentrations. The correlation finally can be expressed in the following forms:

$C_{w}(t)=\frac{C_{o}^{0} V_{o}+C_{o}^{0} V_{w}}{D V_{o}+V_{w}}+\frac{V_{o}\left(D C_{w}^{0}-C_{o}^{0}\right)}{D V_{o}+V_{w}} \exp \left(-\frac{k \cdot t \cdot S\left(D V_{o}+V_{w}\right)}{D V_{o} V_{w}}\right)$

$C_{o}(t)=\frac{D\left(C_{o}^{0} V_{o}+C_{w}^{0} V_{w}\right)}{D V_{o}+V_{w}}-\frac{V_{o}\left(D C_{w}^{0}-C_{o}^{0}\right)}{D V_{o}+V_{w}} \exp \left(-\frac{k \cdot t \cdot S\left(D V_{o}+V_{w}\right)}{D V_{o} V_{w}}\right)(6)$

A good agreement was obtained for the concentration of metal ions between the experimental and correlated values (Figure 2). The correlation coefficients which equal 0.994, 0.996, 0.998, 0.996 for the speed in the range from 30 to $120 \mathrm{rpm}$ were calculated, respectively, for the proposed model.

\section{Adsorption Properties}

The interfacial tension isotherms for investigated extractants are illustrated in Figure $4 \mathrm{a}$ and $\mathrm{b}$. The estimated values of $X i$ and $B$ (estimated from the Rosen equation $^{\mathbf{1 3}}$ ) are presented in Table 3 . TOPO lowers the interfacial tension more effectively and forms a more densely populated monolayer than LIX 54. The values of $\Gamma^{\infty}$ (calculated from the Szyszkowski equation ${ }^{\mathbf{1 3}}$ ) are equal to $1.14 \cdot 10^{-6} \mathrm{~mol} / \mathrm{m}^{2}$ and $0.30 \cdot 10^{-6}$ for TOPO and LIX 54 . In spite of the obvious different interfacial activities of these two compounds the composition of the mixed adsorbed monolayer and the bulk organic phase are very close. The values of $X_{T O P O}$ decrease insignificantly when the interfacial tension increases, however the mean value is close to 0.4 .

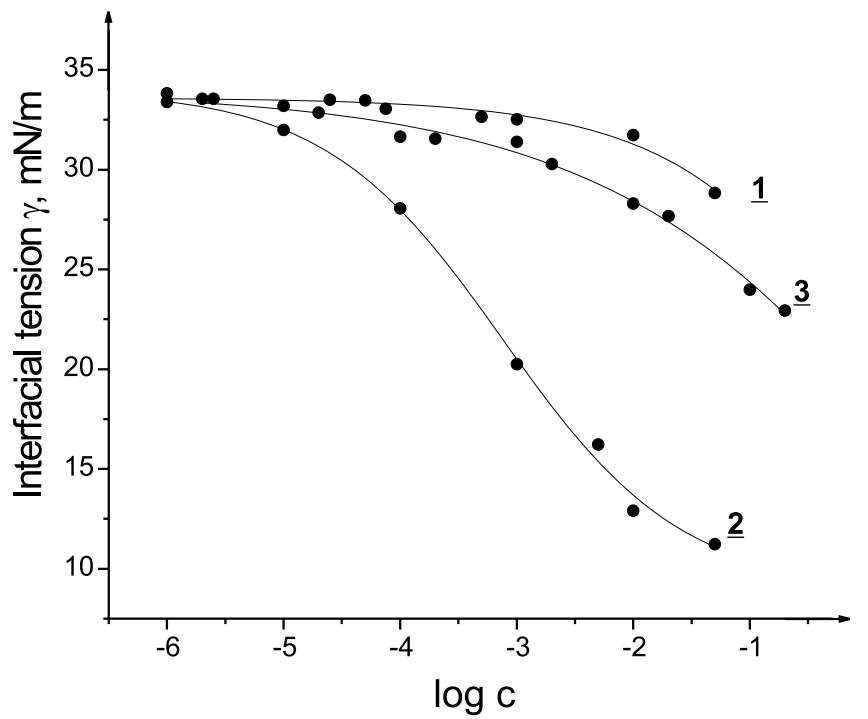

Figure 4a. Interfacial tension isotherms for TOPO (2), LIX 54 (1) and equimolar mixture TOPO+LIX54 ( $\underline{3})$ in water/ toluene system 


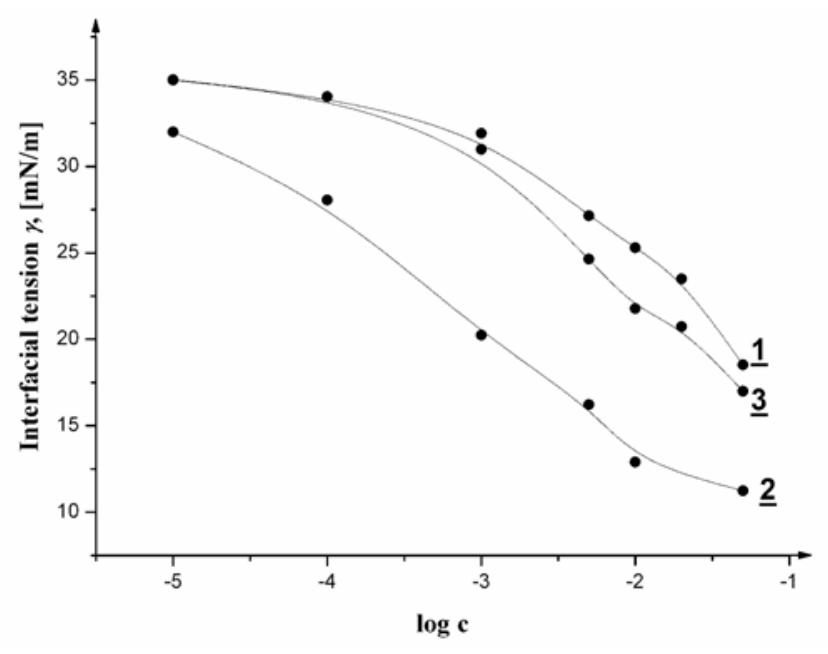

Figure 4b. Interfacial tension isotherms for TOPO (2), Alamine 336 (1) and equimolar mixture (므) in water/toluene system, c in $\mathrm{mol} / \mathrm{dm}^{3}$

Table 3. Values of surface mole fraction XTOPO and molecular interaction parameter $\beta$ in the toluene/water system

\begin{tabular}{|c|c|c|c|c|c|}
\hline $\begin{array}{c}V \\
{[\mathrm{mN} / \mathrm{m}]}\end{array}$ & $X_{\text {TOPO }}$ & $\beta$ & $\begin{array}{c}V \\
{[\mathrm{mN} / \mathrm{m}]}\end{array}$ & $X_{\text {TOPO }}$ & $\beta$ \\
\hline \multicolumn{3}{|c|}{ TOPO/ $\beta$-diketone } & \multicolumn{3}{|c|}{ TOPO/Alamine 336 } \\
\hline 30 & 0.46 & 2.07 & 32 & 0.27 & 4.02 \\
\hline 32 & 0.42 & 2.47 & 28 & 0.29 & 3.61 \\
\hline 33 & 0.40 & 2.46 & 24 & 0.30 & 3.30 \\
\hline
\end{tabular}

The assumption that the molecules of TOPO and LIX 54 interact with each other seems to be rather improbable. The obtained values of $\beta$ (Table 3 ) indicate a clearly repulsive interaction between the adsorbed molecules of these extractants in a mixed monolayer formed at the toluene/water interface. If these extractants do not interact with each other then the characteristic stretching vibrations of the $\mathrm{P}=\mathrm{O}$ group for TOPO should be visible in the FT-IR spectra for the binary mixture of TOPO and LIX 54. This effect is illustrated in the FT-IR spectra in which absorption bands in the $\mathrm{P}=\mathrm{O}$ stretching region are shown for the individual TOPO molecules and for the mixtures in the 1145 and $1144 \mathrm{~cm}^{-1}$ regions, respectively. Thus, the formation of the intermolecular hydrogen bonds between the carbonyl groups of LIX 54 and the phosphoryl group of TOPO is rather improbable because of the presence of the free $\mathrm{P}=\mathrm{O}$ stretching vibration bands in the spectra of the binary mixtures.

As it was mentioned above the addition of LIX 54 to TOPO decreases the extraction efficiency by about $50 \%$. Moreover, in the considered mixture the extractant which has the less extraction efficiency dominated at the interface. Probably the effect of the decreasing extraction efficiency could be explained by the different structure of the adsorbed mixed monolayer with the lower presence of TOPO at the saturated interface, not by an interaction between the reagents.

It was found that the TOPO decreased the interfacial tension at the toluene/water interface much more effectively than Alamine 336. In the light of the above, it seems rather surprising that the molecules of TOPO do not occupy a dominant position at the mixed adsorbed monolayer. The values of the surface mole fraction of Alamine 336 vary in the range from 0.68 to 0.73 . The obtained results proba could be explained in terms of different hydrophilicities of extractants in both considered mixtures. The conclusions presented above are in complete agreement with the results of our earlier study of the coadsorption in the systems with TOPO/TBP described previously ${ }^{13}$. The content of TOPO at the saturated mixed adsorbed monolayer was surprisingly small too. In the case of the mixture of TOPO/Alamine 336 the molecular interaction in a mixed adsorbed monolayer should not be neglected. Positive and high values of the parameter $\beta$ indicate strong repulsive interaction among the molecules extractants adsorbed in the mixed monolayer. The FT-IR spectra of trioctylamine (TOA) (i.e. the active substance of Alamine 336 reagent) and the mixture with TOPO are presented in Figure 5. As it was mentioned above the characteristics for phosphine oxide stretching vibration $\mathrm{P}=\mathrm{O}$ are observed in the region $1150-1100 \mathrm{~cm}^{-1}$. Similar to the mixed system TOPO/LIX 54, in the case of mixture of TOPO and TOA the characteristic absorption bands in the $\mathrm{P}=\mathrm{O}$ stretching region is moved from 1145 to $1144 \mathrm{~cm}^{-1}$ regions for individual TOPO molecules and for mixtures, respectively. The presence of this band indicate the lack of interaction between molecules of extractants in the investigated mixed system.

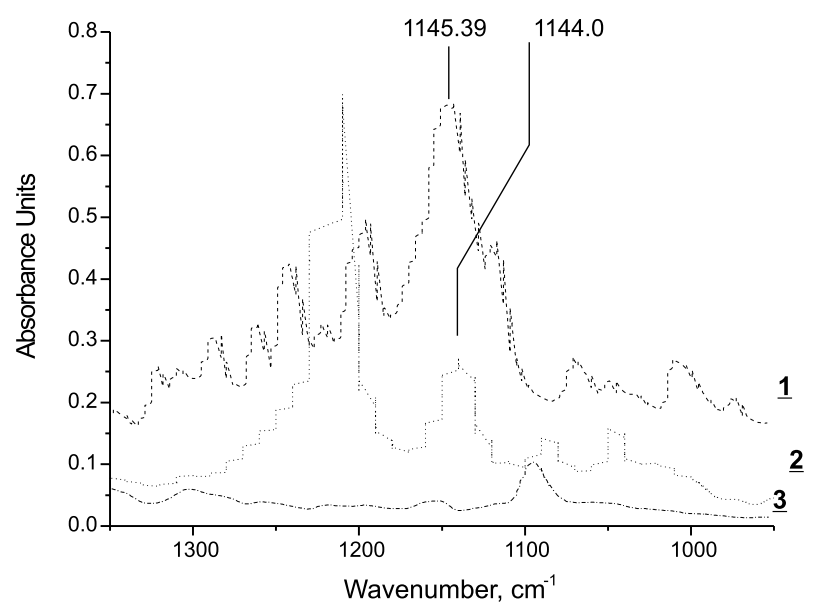

Figure 5. The FT-IR spectra of TOPO ( $\underline{1})$, TOA $(\underline{2})$ and their equimolar binary mixture in chloroform solution ( $\underline{3})$ in the stretching region of $\mathrm{P}=\mathrm{O}$ and $\mathrm{P}$ $\mathrm{O}-\mathrm{C}($ aliph$)$, technique $\mathrm{KBr} 0.2 \mathrm{~mm}$

The values of diffusion coefficients $D$ (estimated from the Ward-Tordai equation ${ }^{14}$ ) according to the dynamic interfacial measurements are presented in Table 4. Taking into account the above results it should be expected that the diffusivity of the mixture of TOPO and Alamine 336 is very close to the $D$ in system with Alamine 336 alone. The values of the $D$ estimated for individual reagents and their mixture are in complete agreement with that assumption. The estimated values of $D$ for the mixture TOPO/Alamine 336 are of the same order of magnitude as the values of $D$ for Alamine 336. In the case of mixture TOPO/LIX54 the average values of $D$ for the mixture was estimated in relation to the appropriate values of $D$ for the individual extractants. Moreover the magnitude of $D$ is affected by the concentration of the compound. 
Table 4. Values of diffusion coefficient for TOPO, LIX 54, ALAMINE ${ }^{\circledR} 336$ and their equimolar mixture in the toluene/water system

\begin{tabular}{|c|c|c|c|c|c|}
\hline \multirow{2}{*}{$\begin{array}{c}c \\
\mathrm{~mol} / \mathrm{dm}^{3}\end{array}$} & LIX54 & Mixture TOPO/LIX 54 & TOPO & $\begin{array}{c}\text { Mixture TOPO/ } \\
\text { ALAMINE }^{\circledR} 336\end{array}$ & ALAMINE \\
\cline { 2 - 6 } & $1.61 \cdot 10^{-8}$ & $2.82 \cdot 10^{-6}$ & $4.45 \cdot 10^{-6}$ & $1.16 \cdot 10^{-7}$ & $8.88 \cdot 10^{-7}$ \\
\hline $10^{-5}$ & $5.16 \cdot 10^{-9}$ & $3.86 \cdot 10^{-8}$ & $4.01 \cdot 10^{-7}$ & $2.58 \cdot 10^{-9}$ & $3.36 \cdot 10^{-9}$ \\
\hline $10^{-4}$ & $4.75 \cdot 10^{-11}$ & $4.49 \cdot 10^{-10}$ & $2.16 \cdot 10^{-9}$ & $5.79 \cdot 10^{-11}$ & $9.58 \cdot 10^{-11}$ \\
\hline $10^{-3}$ & &
\end{tabular}

\section{CONCLUSIONS}

It was found that the extraction efficiency of the investigated extractants are changed in the following order: Alamine 336>TOPO $>\beta$-diketone. The addition of the second extractant to the extraction system decreases the extraction efficiency. Moreover, the results obtained in toluene are much higher in comparison to the extraction of iron(III) in systems with Exxsol D220/230 as organic diluent. The initial rate of $\mathrm{Fe}$ (III) extraction is affected significantly by the composition of the extraction system and the type of the organic diluent. The highest results are obtained for the system with Alamine 336 in toluene as the diluent. A good agreement between the experimental and the correlated values of the concentration of metal ions estimated by the proposed model of mass transfer in a Lewis cell was obtained.

It was shown that the estimated values of the surface mole fraction at the mixed monolayer obtained from the interfacial tension measurements can be well correlated with the extraction data under similar conditions.

The FT-IR spectra of the investigated systems indicated that the extractants do not interact with each other Probably the effect of the decreasing extraction efficiency could be explained by the different structure of the adsorbed mixed monolayer with the lower presence of TOPO at the saturated interface, not by interaction between the reagents.

\section{ACKNOWLEDGMENTS}

The work described in this paper was supported by DS $-32 / 067 / 2011$.

\section{LITERATURE CITED}

1. Mishra, R.K., Rout, P.C., Sarangi, K. \& Nathsarma, K.C. (2010). A comparative study on extraction of $\mathrm{Fe}(\mathrm{III})$ from chloride leach liquor using TBP, Cyanex 921 and Cyanex 923, Hydrometallurgy 104, 298-303. DOI:10.1016/j.hydromet. 2010.07.003.

2. Saji, J. \& Reddy, M.L.P. (2001). Liquid-liquid extraction separation of iron(III) from titania wastes using TBP-MIBK mixed solvent system, Hydrometallurgy 61, 81-87. DOI: 10.1016/ S0304-386X(01)00146-3.

3. Hirato, T., Zhi-Chu, W., Yamada, Y., \& Majima, H. (1992). Improvement of the stripping characteristics of Fe(III) utilizing a mixture of di (2-ethylhexyl) phosphoric acid and tri-n-butyl phosphate, Hydrometallurgy 28, 81-93.

4. Agrawal, A., Kumari, S., Ray, B.C. \& Sahu, K.K. (2007). Extraction of acid and iron values from sulphate waste pickle liquor of a steel industry by solvent extraction route, Hydrometallurgy 88, 58-66. DOI: 10.1016/j.hydromet. 2007.04.001.

5. El-Nadi, Y.A. \& El-Hefny, N.E. (2010). Removal of iron from $\mathrm{Cr}$-electroplating solution by extraction with $\operatorname{di}(2-$ ethylhexyl)phosphoric acid in kerosene, Chemical Eng. Process. 49 159-164, DOI: 10.1016/j.cep.2010.01.004.

6. Lee, M.-S. \& Lee K.J. (2005). Separation of iron and nickel from a spent $\mathrm{FeCl} 3$ etching solution by solvent extraction, Hydrometallurgy 80 163-169, DOI: 10.1016/j.hydromet. 2005.06.010.

7. Ismael, M.R.C. \& Carvalho, J.M.R. (2003). Iron recovery from sulphate leach liquors in zinc hydrometallurgy, Minerals Engineering 16, 31-39.

8. Cierpiszewski, R., Miesiąc, I., Regel-Rosocka, M., Sastre, A.M., \& Szymanowski, J. (2002). Removal of zinc(II) from spent hydrochloric acid solutions from zinc hot galvanizing plants, Ind. Chem. Eng. Res. 41, 598-603.

9. Biswas, R.K., \& Begun, D.A. (1998). Extraction of $\mathrm{Fe}^{3+}$ from chloride solution by D2EHPA in kerosene, Hydrometallurgy 50, 153-168.

10. Cierpiszewski, R., \& Prochaska, K. (2003). Ekstrakcja żelaza(III) w modelowych układach ekstrakcyjnych z organofosforowymi ekstrahentami, Przem. Chem. 82, 739-743.

11. Bandyopadhyay, M., Datta, S., \& Sanya, S. K. (1996). Correlation of mass transfer coefficients for tellurium (IV) extraction with instantaneous reaction in modified Lewis cell, Hydrometalllurgy 42, 115-123.

12. Marszałkowska, B., Sobczyńska, A. \& Wiśniewski, M. (2008). Kinetics of Zinc and iron Ion extraction from acidic solutions with phosphonium ionic liquid, XXXIII International Symposium "Ars Separatoria 2008", July 2008 (pp. 5255). Toruń, Poland.

13. Prochaska, K., \& Staszak, K. (2005). Adsorption at the liquid/liquid interface in mixed systems with hydrophobic extractants and modifiers, J. Colloid Interface Sci. 285, 1-8. DOI: $10.1016 /$ j.jcis.2004.11.037.

14. Fainerman, V.B., Makievski, A.V., \& Miller, R. (1994). Analysis of dynamic surface tension of Na-alkyl sulphate solutions, based on asymptotic solutions of adsorption kinetics equations, Colloid Surface $A$ 87, 61-69. 